\title{
A comparative molecular analysis of two genotypes of Solanum lycopersicum in respect of the expression of selected salt responsive genes in leaves and roots
}

\author{
Chaitali Roy \\ Division of Plant Biology, Bose Institute, Kolkata, India
}

\begin{abstract}
Plant salt tolerance is a complex trait controlled by multiple genes. In recent years, considerable attention has been directed toward elucidating the molecular basis of plant salt tolerance, and numerous salt related genes have been identified. High salinity is one of the most serious threats to crop production. To understand better the molecular basis of plant responses to salt stress, a comprehensive knowledge of the up-and down-regulating genes under salt stress is necessary. Solanum lycopersicum is a moderately salt tolerant crop species with considerable economic importance in salinity affected arid and semi-arid regions of the world. In this study, the tomato cultivars "Pusa Ruby" (PR) and "Punjab Keshari" (PK) were used for transcriptional profiling under salinity stress ( $200 \mathrm{mM} \mathrm{NaCl}$ for $6 \mathrm{~h}$ ), using semi-quantitative RT-PCR. The experiment was designed to target ten defense related genes in roots and leaves of two-month-old plants. A comparable transcript expression profile of up-regulated and down-regulated genes has been created in two different varieties of tomato, in response to salinity. The study confirmed that transcriptional responses differed in leaves and roots, indicating that the molecular mechanisms for responses to the stress in tomato leaves were distinct from those in the roots. Our results revealed a differential expression of all the targeted genes under study in both cultivars of tomato. A higher level of expression of stress responsive genes in $\mathrm{PK}$ leaves in comparison to $\mathrm{PR}$ leaves, together with a much higher basal expression of the targeted genes targeted in our study suggested a more effective defense system in PK.
\end{abstract}

Key words: salt stress, tomato cultivars, stress inducible genes

\section{Introduction}

Salt stress is one of the main abiotic stresses which limit the productivity and geographical distribution of plants. High concentrations of salt in soils are responsible for substantial decreases in the yield of a wide variety of crops all over the world (Tester and Davenport, 2003). The specific toxicity resulting from the accumulation of high concentrations of $\mathrm{Na}^{+}$and $\mathrm{Cl}^{-}$in plants provokes various physiological and biochemical alterations and, in consequence, inhibits plant growth and production (Maggio et al., 2004; Munns, 2005). It is necessary to understand how plants respond and adapt to this stress in order to prevent crop yield losses. Salt tolerance might be affected by the expression of many different genes which are involved in different pathways, such as ion compartmentation, ion extrusion, ion selecti- vity, compatible solute synthesis and reactive oxygen species (ROS) scavenging (Blumwald et al., 2000; Zhu, 2001; Zhu, 2003; Munns and Tester, 2008). Cultivated tomato, one of the most important vegetable crops in the world, is moderately sensitive to salinity. The existence of salt tolerant varieties of several wild tomato species has made tomato a model crop for comparative studies on the mechanisms of salt tolerance. Our previous investigations have focused on the physiological and biochemical characterization of a few tomato cultivars.

The regulation of gene expression is one of the key phenomena in plants, by which they respond and try to adapt to salt stress. One of the most intriguing examples of such salt-induced gene regulation in plants is the saltinduced activation of the phosphorylation/kinase cascade, followed by the activation of various transcription 
factors (Xiong et al., 2002). To re-establish cell homeostasis and normal functioning under salt stress, the activated transcription factors regulate either the expression of genes which encode proteins contributing to salt tolerance, or the activity of enzymes which are involved in pathways leading to the protection and repair of cells under salt stress (Flowers, 2004; Munns, 2005). Plants use different strategies to survive the problem of salinity. Some of these strategies of salt tolerance involve altering their germination and growth rates (Debez et al., 2004), accumulating osmolytes, and increasing the activity of an antioxidant system etc. (Ashraf and Foolad, 2007; Fu et al., 2013; Talei et al., 2013). Protection against various environmental stresses has been well documented (Khan and Singh, 2008; Gill et al., 2011). During the course of plant growth, the form and functions of various organs undergo significant changes and the ability of the plant to react to salinity stress depends on the genes that are expressed at the developmental stage, during which the stress is imposed (Epstein and Rains, 1987). Osmotic adjustment in plants subjected to salt stress can be achieved by the accumulation of high concentrations of either inorganic ions or low molecular weight organic solutes. Although both of these play a crucial role in higher plants grown under saline conditions, their relative contribution varies among species and cultivars, and even between different compartments within the same plant (Ashraf, 1994; Greenway and Munns, 1980). Salt-induced changes in the transcriptome profile in roots of two tomato cultivars with distinct salt tolerance were compared (Ouyang et al., 2007). It was also suggested that the molecular mechanisms for responses to the stress in leaves are distinct from those in roots (Qing et al., 2009).

During the past few decades significant progress has been made in the identification and characterization of genes, enzymes or compounds with significant roles in plant salt tolerance at the cellular or organism level (Allakhverdiev et al., 1999; Apse et al., 1999; Bohnert and Shen, 1999; Grover et al., 1999; Chinnusamy et al., 2005; Cuartero et al., 2009; Plett and Moller, 2010). Manipulations in the production of such elements which are important for salt tolerance, e.g. through transgenic approaches, have resulted in the development of plants from various species with enhanced salt tolerance (Apse et al., 1999; Serrano et al., 1999; Zhang and Blumwald, 2001).
The aim of this study was to compare the responses of two tomato cultivars to salinity. To help decipher the complex molecular mechanisms of plant salt tolerance, a strategy of RT-cDNA was used to find out how the two cultivars of tomato differ regarding the effect of salt stress on the same set of stress-regulated genes. Selection was made for particular "genes of interest" for our investigation based on their known or hypothesized functions and involvement in stress responses in different tomato cultivars. To understand the expression pattern of various genes under salt stress conditions, we developed a comparative profile based on ten stress-related genes, in two different varieties of tomato. Ten genes ( $R a b 1 A, R a b 1 B$, Rab1C, Rab11a, Aquaporin, ZFP, NAC1, CBF1, WRKY6 and $E R 43$ ) were identified by searches of the EST database (Table 1). Rab GTPases play a central role in the process of vesicle trafficking in eukaryotic cells (Molendijk et al., 2004; Grosshans et al., 2006). Aquaporins (AQ) are channel proteins present in the plasma membrane as well as in the intracellular membranes of cells, where they facilitate the transport of water, neutral solutes or gasses. ZFP, the leucine zipper-based transcription factors with well-established roles in plant development and biological processes have also been shown to induce stress tolerance in plants (Liao et al., 2008; Ni et al., 2008). The NAC [No apical meristem (NAM), Arabidopsis transcription activation factor (ATAF), Cup-shaped cotyledon (CUC)] protein family is one of the largest families of plant specific transcription factors (Olsen et al., 2005). C-Repeat binding factors ( $\mathrm{CBFs}$ ), a family of transcription factors (TFs), regulate the expression of COR (cold regulated) genes on cold stress exposure. WRKY TFs are key regulators of many processes in plants. These include the responses to biotic and abiotic stresses. Members of the ER (ethylene responsive) family are involved in the cross-talk of different kinds of abiotic stress and signaling pathways, in that they are highly regulated by various kinds of abiotic factors and plant hormones, such as low temperature, ethylene, drought, high salinity, abscisic acid, and jasmonate (Liu et al., 1998; Zhang et al., 2004). A comparative transcript profiling will be helpful to evaluate the relative performances of $\mathrm{cv}$. PR and cv. PK in combating salt stress. In this report, two cultivars of $S$. lycopersicum PR and $\mathrm{PK}$ have been compared in terms of their molecular responses to salt stress. A semi-quantitative RT-PCR analysis with ten stress inducible genes was performed to assess their regulation by salt stress. 
Table 1. List of genes and their short descriptions, which were used for designing primers for RT-PCR analysis

\begin{tabular}{|c|c|c|c|}
\hline $\begin{array}{c}\text { Gene name } \\
\text { Solanum lycopersicum }\end{array}$ & $\begin{array}{l}\text { Accssn. } \\
\text { no. } \\
\text { of NCBI }\end{array}$ & $\begin{array}{l}\text { Sizes } \\
\text { of the cDNAs } \\
\text { base pair }\end{array}$ & $\begin{array}{l}\text { Source tomato sp. } \\
\text { and annotation }\end{array}$ \\
\hline$R a b 1 A$ & U38464 & 611 & $\begin{array}{l}\text { LA1221, } \\
\text { Small GTP binding protein }\end{array}$ \\
\hline $\operatorname{Rab1B}$ & U38465 & 611 & $\begin{array}{l}\text { LA1221, } \\
\text { Small GTP binding protein }\end{array}$ \\
\hline $\operatorname{Rab1C}$ & U38466 & 611 & $\begin{array}{l}\text { LA1221, } \\
\text { Small GTP binding protein }\end{array}$ \\
\hline Rab11a & AJ245570 & 656 & $\begin{array}{l}\text { Ailsa Craig, } \\
\text { Rab11GTPase putative role in secretion in cell wall }\end{array}$ \\
\hline Aquaporin & AB211518 & 800 & $\begin{array}{l}\text { Micro-tom, } \\
\text { Water channel protein }\end{array}$ \\
\hline Zinc finger protein $(Z F P)$ & ВT013336 & 900 & $\begin{array}{l}\text { Micro-tom, } \\
\text { DNA binding transcription Factor }\end{array}$ \\
\hline$N A C 1$ & EU670750 & 905 & $\begin{array}{l}\text { LA2711, } \\
\text { Pathogen responsive transcription factor, NAM like protein }\end{array}$ \\
\hline$C B F 1$ & AY034473 & 650 & $\begin{array}{l}\text { TA496, } \\
\text { Cold responsive } \\
\text { Putative transcription factor }\end{array}$ \\
\hline WRKYG & AK322575 & 881 & $\begin{array}{l}\text { Micro-tom, } \\
\text { Transcription factors invoved in Plant defense mechanism }\end{array}$ \\
\hline ER43 & AF096249 & 650 & $\begin{array}{l}\text { Evita, } \\
\text { Ethylene responsive gene (Ethylene responsive Factor } 43 \text { ) }\end{array}$ \\
\hline
\end{tabular}

\section{Materials and methods}

\section{Plant material and growth conditions}

Seeds of local cultivars of $S$. lycopersicum, e.g. cv. "Pusa Ruby" and cv. "Punjab Keshari", were purchased from Amtala Seed Center, Amtala, West Bengal.

The seeds were surface sterilized in $0.1 \% \mathrm{HgCl}_{2}$ for 10 $\mathrm{min}$, and then rinsed with water. Selected seeds were germinated aseptically on petri dishes containing moistened filter paper. After three days, germinated seeds were grown for another twelve days. These seedlings were then transferred to trays containing fresh $0.25 \times$ MS (Murashige and Skoog, 1962) (Sigma) liquid media. Plants in the tray were grown in vivo for another 45 days in a tissue culture room ( $16 \mathrm{~h}$ dark and $8 \mathrm{~h}$ light period, 25 $\left.26^{\circ} \mathrm{C}\right)$. The media were replaced weekly. For salt treatment, eight-week-old plants in a tray containing 0.25 $\times$ strength MS solution were supplemented with 0 and $200 \mathrm{mM} \mathrm{NaCl}$ and exposed for 6 hours. Then, the plants were washed thoroughly with sterile de-ionized water, their leaves and roots were sampled separately and stored at $-80^{\circ} \mathrm{C}$ for investigations. Three replicates were performed for each treatment.

\section{Specific primers}

Annotations of the ten genes under study are listed in Table 1. Primers specific to cDNAs of the targeted genes were designed and used in RT-PCR experiments for amplification of the full length cDNAs, as shown in supplementary Table S1.

\section{RNA extraction and quantification}

Total RNA was isolated from roots and leaves using a hot phenol method (Kay, 1987). Next, it was quantified using a NanoDrop Spectrophotometer (NanoDrop 1000, Thermo Scientific, USA). The integrity of total RNA was assessed by gel electrophoresis (standard 1.2\% agarose gel).

\section{RT-PCR}

RNA samples were treated with DNaseI to remove residual traces of DNA. The first-strand cDNA was syn- 
thesized from $5 \mu \mathrm{g}$ of total RNA with oligo(dT) and Sensiscript ${ }^{\mathrm{TM}}$ reverse transcriptase (Qiagen), according to the manufacturer's instructions, in a final volume of $20 \mu \mathrm{l}$. The reverse transcription mix was diluted five times and $2 \mu \mathrm{l}$ was used for general PCR using Taq polymerase (Genetbio) with these thermocycling conditions: $1 \times 94^{\circ} \mathrm{C} / 2 \mathrm{~min}, 30 \times 94^{\circ} \mathrm{C} / 60 \mathrm{~s}, 1 \times\left(55\right.$ to $\left.59^{\circ} \mathrm{C}\right) / 60 \mathrm{~s}$, and $1 \times 72^{\circ} \mathrm{C} / 11.5 \mathrm{~min}$ and held at $4{ }^{\circ} \mathrm{C}$. Separate PCR reactions were carried out in a Thermal Cycler (PTC200, Peltier Thermal Cycler, MJ Research, USA) for different targeted genes with specific primers. The amplified fragments were purified and directly sequenced without an intermediary cloning step using a BigDye Terminator version 3.1 Cycle Sequencing kit (Applied Biosystems, Foster City, USA). The electrophoresis and data collection were performed on an ABI Prism 3100XL Genetic analyzer (Hitachi Applied Biosystems).

\section{Gene expression and data analysis}

Various techniques have been employed to study gene expression profiles in plants under different abiotic stresses. Among such techniques, PCR-based protocols offer the simplest approach to study differential expressions of genes under varying levels of salt stress, various time intervals, and different developmental stages or in various plant tissues. Here, transcript levels of Rab1A, Rab1B, Rab1C, Rab11a, Aquaporin, ZFP, NAC1, CBF1, WRKY6 and ER43 genes, in two tomato cultivars PR and PK (treated and untreated), were examined and compared.

RT-PCR products (supplementry Fig. S4) were analyzed on $1.0 \%(\mathrm{w} / \mathrm{v})$ agarose gels containing ethidium bromide $(0.5 \mu \mathrm{g} / \mathrm{ml})$. The products were documented by digital imaging after visualization under ultraviolet light. The band intensity was expressed as relative absorbance units using a GelDoc Imaging System, QuantityOne (BioRad, USA). Densitometer read-outs were normalized to the values obtained for the housekeeping gene 18SrRNA.

A two-color based heat map of semi-quantitative RT-PCR was generated using Multi-Experiment Viewer (MeV_4_7_7_r2621_win.zip/tm4) to provide a visual impression of how the various sample groups are related. In this experiment, two-month-old plants (PR and PK) were subjected to $200 \mathrm{mM} \mathrm{NaCl}$ stress for a period of $6 \mathrm{~h}$. The normalized expression intensity values of expression data were imported to the TM4 software suite to generate a heat map. All data are presented as a mean

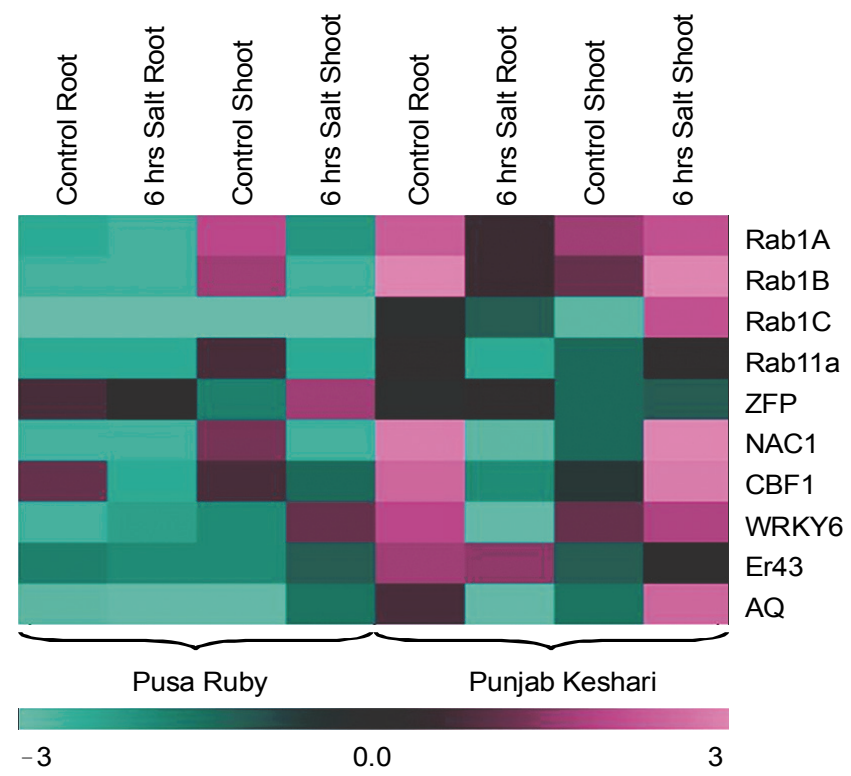

Fig. 1. Expression Heat map for relative expression of 10 targeted genes detected by semi-quantitative RT-PCR in 2 varieties of tomato, using Tm4 "Multi Experiment Viewer". Gene names appear to the right of the figure and each column represents samples from treated or untreated organs. The color bar representing $\log _{2}$ transformed values where pink indicates upregulation and green indicates down-regulation. Genes listed at the right side have been described in more detail in text and in Table 1

$\pm \mathrm{SE}$ of three replicates. The expression levels of selected genes were then compared (Fig. 1 and Table 1).

\section{Results}

\section{Performance of Pusa Ruby and Punjab Keshari under $\mathrm{NaCl}$ stress}

To characterize the differences between PR and PK in terms of salt tolerance in respect to the genes under study, two-month-old plantlets of both genotypes were treated hydroponically for $6 \mathrm{~h}$ with different concentrations of $\mathrm{NaCl}(0$ to $200 \mathrm{mM})$. When a higher concentration of salt $(>200 \mathrm{mM})$ was applied, plants of both genotypes were severely wilted within $30 \mathrm{~min}$.

The effect of different salt concentrations $(0,50$, 100,150 and $200 \mathrm{mM}$ ) on in vitro grown plantlets was investigated (supplementary Fig. S2). Under $200 \mathrm{mM}$ $\mathrm{NaCl}$, chlorosis was obvious only in $\mathrm{PR}$, although a slower growth was observed in both genotypes. The survival rate for PR decreased after 35 days, but PK plants were able to survive. Under $200 \mathrm{mM} \mathrm{NaCl}$, the survival rate for PK after 30 days was still higher than that for $\mathrm{PR}$. These results indicated that PK may be more salt 
tolerant than PR. The cross-sectional view of root sections of both the treated and untreated plants showed that the roots became transfigured under salt stress. The cross-sectional area of the vascular cylinder showed significant differences between all treatments, decreasing with the increasing concentration of $\mathrm{NaCl}$. With regard to the parenchyma, only those treated with the highest salt concentrations were significantly different to the controls. Epidermis cells in the investigated roots brushed off under salt stress. In addition, the pericycle cells shrank and the epidermis cells separated from the cortex cells (supplementary Fig. S3).

\section{Gene expression profiling}

In order to gain a better understanding of the mechanism underlying the salt tolerance of $\mathrm{PR}$ and $\mathrm{PK}$, the transcriptome changes after $6 \mathrm{~h}$ salt stress were investigated using RT-PCR for ten selected genes. A $6 \mathrm{~h}$ treatment with $200 \mathrm{mM} \mathrm{NaCl}$ was used to focus mainly on the early responses to salinity shock.

In general, differential expression patterns were obtained in the putative salt-tolerant genotype PK and the putative moderately salt tolerant genotype PR. Upon $6 \mathrm{~h}$ salt stress, all the ten genes were up-regulated in leaves and down-regulated in roots of cv. PK (Fig. 1 and supplementary Fig. S4), except for $Z F P$ which was up-regulated in the roots, whereas in cv. PR all the candidate genes were down-regulated in both tissues (Fig. 1 and supplementary Fig. S4.).

\section{Expression of genes Rab1A, Rab1B, Rab1C and Rab11a under stress and normal growth conditions}

Transcript accumulation in the treated roots and leaves of both the cultivars showed significant differences (Fig. 1 and supplementary Fig. S4).

Under salinity stress, the transcript levels of four genes (Rab1A, $L a b 1 B, R a b 1 C$ and Rab11a) were undetectable in preparations from the roots of cv. PR, whereas they were detectable in the roots of cv. PK. In PR leaves, the expression of three genes ( $R a b 1 B, R a b 1 C$ and Rab11a) was undetectable and the expression of Rab1A was only detected at a low level. The stress driven expression of these genes was quite high in the leaves of $\mathrm{PK}$, whereas in roots all of them were down-regulated (Fig. 1 and supplementary Fig. S4).

Under normal growth conditions in cv. PR, the basal expression of Rab1A, Rab1B and Rab11a was high in leaves, but the expression of all four genes was low or undetectable in roots. In cv. PK, the basal expression of Rab1A was found to be quite high in both roots and leaves. $R a b 1 B / 1 C / 11 a$ transcripts were found to be abundant only in roots, whereas in leaves their expression was quite low (Fig. 1 and supplementary Fig. S4).

Expression of ZFP, NAC1, CBF1, WRKYG and ER43 under stress and normal growth conditions

Salinity stress induced three-fold higher accumulation of transcripts of $C B F 1$ and $N A C 1$ in leaves of cv. PK, but lowered WRKYG expression in leaves. The transcripts of $N A C 1, C B F 1$ and $W R K Y 6$ were repressed in the treated roots of PK plants. All of these five genes, except for $Z F P$, were highly repressed in the leaves of PR, whereas three of them (WRKYG, NAC1 and ER43) remained unaltered in the roots. The $Z F P$ gene was upregulated to some extent in both organs of $\mathrm{PK}$ and moderately in leaves of PR. It was repressed by about 30\% in roots of cv. PR (Fig. 1 and supplementary Fig. S4).

Under unstressed conditions, the basal expression of these five genes (ZFP, NAC1, CBF1, WRKY6 and $E R 43)$ in $\mathrm{PK}$ was found to be higher in roots than in leaves (Fig. 1 and S4). In the case of cv. PR, apart from $Z F P$, the other four genes were abundant in leaves, whereas in roots the expression levels of WRKY6, NAC1 and ER43 remained undetectable.

\section{Expression of the Aquaporin gene under stress and normal growth conditions}

Aquaporin gene expression after treatment with $200 \mathrm{mM} \mathrm{NaCl}$ for $6 \mathrm{~h}$ was induced only in the leaves of cv. PK. In untreated leaves of PK, its expression was low but a three-fold enhancement was detected after $\mathrm{NaCl}$ treatment. In roots of cv. PK it was significantly downregulated. PR showed a high constitutive level of expression of this gene in leaves which were repressed when treated. Under both conditions, the transcript levels of $\mathrm{AQ}$ were undetectable in roots of $\mathrm{PR}$.

\section{Discussion}

To improve salt tolerance in cultivated tomato, it is necessary to understand the mechanisms underlying its salt tolerance. Salt stress and many other biotic and abiotic stresses are coordinately regulated by different interconnected pathways (Ludwig et al., 2005; Ma et al., 2006). 
Salt tolerance determinant genes can be categorized into two functional groups (Hasegawa et al., 2000). The first includes effectors responsible for processes that are necessary for stress alleviation or adaptation. The second consists of regulatory genes which include transcription factors (TFs) (Hasegawa et al., 2000). The functional characterization of various TFs under salt-stress conditions may provide essential information. For example, overexpression of certain stress-responsive TFs in transgenic crops may lead to an enhanced plant salt tolerance and improved crop productivity under saline conditions. The TF genes in our study, i.e. WRKY6, $N A C 1, Z F P, C B F 1$ and $E R 43$, were highly induced in stressed conditions especially in the leaves of PK. There are several reports of such induction of TFs in abiotic stress (Sakamoto et al., 2004; Huang et al., 2009; Hsieh, 2002; Yamaguchi-Shinozaki and Shinozaki, 2006; Tao et al., 2011). In addition, the high level of constitutive expression of genes coding for these TFs, even under unstressed conditions, may be the underlying reason why PK developed a much higher salt tolerance than PR.

C-Repeat binding factors (CBFs) play a vital role in protecting plants from the deleterious effects of cold stress (Thomashow, 2010). In the present study, cultivar PK of tomato displayed accumulation of $C B F 1$ transcripts in response to salt treatment. However, the extent of the increase in transcript abundance was significantly higher in treated leaves, while it was down-regulated in the roots. Such up-regulation of TFs must have also contributed to PK's high tolerance. There have been reports indicating that constitutive overexpression of CBF1 in transgenic tomato increased drought, chilling and oxidative stress tolerance (Hsieh, 2002). Similarly, transgenic Arabidopsis overexpressing CBF-type genes displayed strong tolerance to drought, high salinity and freezing with growth retardation (Yamaguchi-Shinozaki and Shinozaki, 2006).

Genes from the NAC family have been found to participate in various biological processes including development, biotic and abiotic stresses (Hegedus et al., 2003; Guo et al., 2005). While in our experiments a high level of $N A C 1$ transcript was observed in treated leaves of $\mathrm{PK}$, the same gene was found repressed in leaves and roots of cv. PR, even though it was highly expressed in control leaves. In Arabidopsis, three NAC proteins (ANAC019, ANAC055, and ANAC072) have been identified (Yamaguchi-Shinozaki and Shinozaki, 2006). Over- accumulation of these NAC TFs resulted in up-regulation of several stress-inducible genes and improved drought tolerance of the transgenic Arabidopsis plants. Up-regulation of these genes caused a significantly increased tolerance to abiotic stress in the transgenic lines (Yamaguchi-Shinozaki and Shinozaki, 2006). An Arabidopsis NAC gene, AtNAC2, has been found to be involved in the salt stress response and in lateral root development (He et al., 2005). It is worth noting that the $N A C 1$ gene in this study is precisely the one identified by Selth et al. (2005) as being involved in interactions with a tomato leaf curl virus (TLCV). Selth reported that SINAC1 gene expression was up-regulated in response to TLCV infection. TLCV induces synthesis of NAC1 which interacts with the REn (replication enhancer) and thus appears to be involved in viral replication. So, it seems that NAC genes play an important role in the cross-linking of different signaling pathways.

The association between zinc finger TFs and plant salt tolerance has been reported previously. As far as our findings are concerned, under stressed conditions the expression of $Z F P$ was found to be significantly enhanced only in the leaves of PR. However, in PK the basal levels of $Z F P$ transcripts, in both tissues, were a small amount higher in comparison to PR. Additionally, accumulation of the transcript enhanced marginally under stress in both organs. PK demonstrated a marginal increase in its expression in both organs under stress. There are reports where transgenic rice plants overexpressing ZFP245 have shown significant tolerance to cold and drought stresses (Huang et al., 2009). Earlier reports have also indicated that the expression of genes from the zinc finger TF family was highly induced by severe salt stress. In particular, rice zinc-finger gene OSISAP1, and two Arabidopsis Cys2/His2-type zincfinger genes - $A Z F 2$ and $S T Z$ - have been found to be strongly induced by different types of stress, including high salt treatment (Mukhopadhyay et al., 2004; Sakamoto et al., 2004). Overexpression of OSISAP1 in transgenic tobacco conferred tolerance to cold, dehydration, and salt stress at the seed-germination/seedling stage (Mukhopadhyay et al., 2004).

Accumulation of WRKY6 transcript was detected in leaves of both cultivars in stressed and unstressed conditions. Most of the genes under study, including WRKYG, were down-regulated in treated roots of both the cultivars. Transgenic rice plants overexpressing OsWRKY45-2 
showed increased ABA sensitivity and salt stress tolerance (Tao et al., 2011). WRKYs have diverse roles in plant development and stress regulation (Nakashima et al., 2007; Zhou et al., 2002 and 2008). Generally, over-accumulation of TFs controlling multiple genes from various pathways may lead to attaining tolerance against multiple stresses (Sreenivasulu et al., 2007). Several recent reports have emphasized the importance of TFs in mediating responses against abiotic stresses.

As PK showed better tolerance to salinity stress, the transcript levels for the TFs were also found to be higher in PK, including that for ER43, which is an ethylene responsive element binding factor. Ethylene is required for salt-stress signaling and adaptation (Ma et al., 2006). Tomato contains multiple homologous genes coding for ethylene receptors that are expressed differentially in fruit ripening and defense response processes. In the presented experiments, the transcript level of ER43 enhanced two-fold in both organs of PK, which indicates that the plant hormone ethylene plays an important role in tomato salt tolerance.

The expression of small GTP (smGTP) genes (Rab1A, Rab1B, Rab1C and Rab11a) was found to be strongly induced by salt only in leaves of PK. Additionally, transcripts of all the mentioned Rab genes were found to be abundant in PK under normal conditions and their abundance was even higher in roots than in leaves. While in PR the basal level of the transcripts was high in untreated leaves, none was detectable in roots under normal growth conditions. It is to be noted that the $R a b 1 C$ transcript was not detected in unstressed or stressed PR plants. This suggests that stress inducible signaling pathways are constitutively active in PK even under unstressed conditions and must have contributed to a much higher tolerance of this cultivar compared to that of PR. Our observation of the activation of expression of smGTP genes during salt stress is consistent with the current understanding of the transcriptional regulatory networks utilized by plants to survive abiotic stresses (Yamaguchi-Shinozaki and Shinozaki, 2006). The transcription levels were found to be high in leaves, even though the leaves were not in direct contact with the $\mathrm{NaCl}$ medium. These relative changes (higher transcript accumulation in $\mathrm{NaCl}$ treated leaves) are probably due to long distance signaling through hormones, e.g. ABA, or nutrient movement from root to leaf.

Under normal growth conditions, the transcript abundance of $\mathrm{AQ}$ gene in leaves was twice as high in $\mathrm{PR}$ than in PK. The control PR leaves show quite a high expression of $\mathrm{AQ}$ gene, which was not detected in the treated leaf samples. Our expression data show that the water channel proteins of the cell membrane (AQ) are constitutively abundant in untreated leaves of $\mathrm{PR}$, but extensively down-regulated in salt treated plants. This must be to limit the initial water loss. We have to assume that a high level of a basal AQ gene expression might be to facilitate transcellular water movement. In $200 \mathrm{mM} \mathrm{NaCl}$, the expression of the $A Q$ gene was significantly up-regulated in leaves and down-regulated in roots of cv. PK, while it was highly repressed in leaves or roots of PR. Earlier reports have suggested that the expression of $\mathrm{AQ}$ genes may be down-regulated due to the reduction of cell hydraulic conductivity (Shope et al., 2006). In roots of most of the plant species investigated so far, drought or salt stresses resulted in a marked decrease in transcript levels of $\mathrm{AQ}$ gene. In Arabidopsis, exposed to $100 \mathrm{mM} \mathrm{NaCl}$, this transcript is repressed by $70 \%$ (Javot et al., 2002). In corn, a coordinated down-regulation of most aquaporin transcripts has also been noticed (Alexandersson et al., 2005). An increased level of aquaporin channel proteins in the aerial parts of PK under salinity stress might have facilitated a water flow to the vegetative parts. Additionally, studies on Hordeum vulgare (barley) leaves have suggested that an increased abundance of $H_{V} P I P 16$ transcripts, in response to salt, may reflect the role of this aquaporin in promoting residual growth of the leaf under stress (Fricke et al., 2006).

The results of our previous biochemical experiments (Roy and Sengupta, 2014) with leaves of three twomonth-old tomato cultivars (PR, PK and Ailsa Craig) indicated that a $6 \mathrm{~h}$ salt shock treatment with $200 \mathrm{mM}$ $\mathrm{NaCl}$ was sufficient to cause significant changes in the content of such biochemical constituents as proline, polyamines (PAs), cysteine, $\mathrm{H}_{2} \mathrm{O}_{2}$, MDA (malondialdehyde), and pigments (anthocyanin and carotenoids). Significant accumulation of osmoprotectants and antioxidants proved that the defense system of PK is much stronger than that of $\mathrm{PR}$, keeping reactive oxygen species and MDA under control. Proline is one of the most important osmoprotectants in plants. Under salt stress, most plant species exhibit a remarkable increase in proline content (Patel and Pandey, 2008; Dasgan et al., 2009). Extremely large amounts of proline accumulation have also been found in cv. PK. Our earlier study also 
showed that PK produced a higher level of polyamines (putrescine and spermidine) when treated with $200 \mathrm{mM}$ $\mathrm{NaCl}$. It is noteworthy that these data presented here correlate with the result of our previous biochemical experiments, where PK was also found to be more stress resistant than cv. PR in respect to accumulation of transcripts of the stress responsive genes under study.

\section{Conclusions}

This report proposes that comparative expression profiling of two cultivars of S. lycopersicum, PR and PK, would expedite the identification of genes with important roles in salt stress tolerance. An RT-PCR analysis with ten different stress inducible genes has revealed a differential gene regulation in the two cultivars during an early phase of the stress. The transcriptional responses varied in leaves and roots, showing that the molecular mechanisms for responses to the stress are distinct in these organs. The greater extent of up-regulation of stress-responsive genes in $\mathrm{PK}$ suggests that $\mathrm{PK}$ is more salt tolerant than PR. These differences at the transcriptomic level show that cultivars of the same species can use different molecular strategies to cope with unfavorable conditions. The data presented herein enhance our understanding of the molecular mechanisms of tomato responses to salinity stress and lay the groundwork for genetic engineering strategies to improve the stress tolerance of agronomically important species.

\section{Acknowledgements}

The author is thankful to Prof. Sibaji Raha, Director of the Bose Institute. Thanks also go to the Chairperson of the Division of Plant Biology (DPB) Prof. Swati Gupta Bhattacharya. The author is especially grateful to Prof. Tapas Ghose of DPB for his valuable suggestions. The author acknowledges the support of the Central Instrument Facility of the Bose Institute.

\section{References}

Alexandersson E., Fraysse L., Sjovall-Larsen S., Gustavsson S., Fellert M., Karlsson M. (2005) Whole gene family expression and drought stress regulation of aquaporins. Plant Mol. Biol. 59: 469-484.

Allakhverdiev S.I., Nishiyama Y., Suzuki I., Tasaka Y., Murata N. (1999) Genetic engineering of the unsaturation of fatty acids in membrane lipids alters the tolerance of Synechocystisto salt stress. PNAS 96: 5862-5867.

Apse M.P., Aharon G.S., Snedden W.A., Blumwald E. (1999) Salt tolerance conferred by overexpression of a vacuolar $\mathrm{Na}^{+} / \mathrm{H}^{+}$antiport in Arabidopsis. Science 285: 1256-1258.
Ashraf M. (1994) Breeding for salinity tolerance in plants. Crit. Rev. Plant Sci. 13: 17-42.

Ashraf M., Foolad M.R. (2007) Roles of glycine betaine and proline in improving plant abiotic stress resistance. Environ. Exp. Bot. 59: 206-216.

Blumwald E., Aharon G.S., Apse M.P. (2000) Sodium transport in plant cells. Biochim. Biophys. Acta 1465: 140-151.

Bohnert H.J., Shen B. (1999) Transformation and compatible solutes. Sci. Horticult. 78: 237-260.

Chinnusamy V., Jagendorf A., Zhu J.K. (2005) Understanding and improving salt tolerance in plants. Crop Sci. 45: 437448.

Cuartero J., Bolarinj M.C., Moreno V., Pineda B. (2009) Molecular tools for enhancing salinity tolerance in plants. In: Molecular Techniques in Crop Improvement, Ed. Jain S.M., Springer, The Netherlands: 373-405.

Dasgan H.Y., Kusvuran S., Abak K., Leport L., Larher F., Bouchereau A. (2009) The relationship between citrulline accumulation and salt tolerance during the vegetative growth of melon (Cucumismelo L.). Plant Soil Environ. 55: $51-57$.

Debez A., Hamed K.B., Grignon C., Abdelly C. (2004) Salinity effects on germination, growth, and seed production of the halophyte Cakilemaritima. Plant Soil 262: 179-189.

Epstein E., Rains D.W. (1987) Advances in salt tolerance. In: Genetic Aspects of Plant Mineral Nutrition, Eds. Gableman H.W., Loughman B.C., Martinus Nijhoff, Boston: 113-125.

Flowers T.J. (2004) Improving crop salt tolerance. J. Exp. Bot. 55: 307-319.

Fricke W., Akhiyarova G., Wei W., Alexandersson E., Miller A., Kjellbom P.O., Richardson A., Wojciechowski T., Schreiber L., Veselov D., Kudoyarova G., Volkov V. (2006) The short-term growth response to salt of the developing barley leaf. J. Exp. Bot. 57: 1079-1095.

Fu M., Li C., Ma F. (2013) Physiological responses and tolerance to $\mathrm{NaCl}$ stress in different biotypes of Malus prunifolia. Euphytica 189: 101-109.

Gill S.S., Khan N.A., Anjum N.A., Tuteja N. (2011) Amelioration of cadmium stress in crop plants by nutrients management: Morphological, physiological and biochemical aspects. Plant Stress 5: 1-23.

Greenway H., Munns R. (1980) Mechanism of salt tolerance in nonhalophytes. Ann. Rev. Plant Physiol. 31: 149-190.

Grosshans B.L., Ortiz D., Novick P. (2006) Rabs and their effectors: achieving specificity in membrane traffic. PNAS 103: 11821-11827.

Grover A., Sahi C., Sanan N., Grover A. (1999) Taming abiotic stresses in plants through genetic engineering: current strategies and perspective. Plant Sci. 143: 101-111.

Guo H.S., Xie Q., Fei J.F., Chua N.H. (2005) MicroRNA directs $m R N A$ cleavage of the transcription factor NAC1 to downregulate auxin signals for arabidopsis lateral root development. Plant Cell 17: 1376-1386.

Hasegawa P.M., Bressan R.A., Zhu J.K., Bohnert H.J. (2000) Plant cellular and molecular responses to high salinity. Ann. Rev. Plant Physiol. Plant Mol. Biol. 51: 463-499. 
He X.J., Mu R.L., Cao W.H., Zhang Z.G., Zhang J.S., Chen S.Y. (2005) AtNAC2, a transcription factor downstream of ethylene and auxin signaling pathways, is involved in salt stress response and lateral root development. Plant J. 44: 903-916.

Hegedus D., Yu M., Baldwin D., Gruber M., Sharpe A., Parkin I. Whitwill S., Lydiate D. (2003) Molecular characterization of Brassica napus NAC domain transcriptional acti vators induced in response to biotic and abiotic stress. Plant Mol. Biol. 53: 383-397.

Hsieh T.H., Lee J.T., Yang P.T., Chiu L.H., Charng Y.Y., Wang Y.C., Chan M.T. (2002) Heterology expression of the Arabidopsis C-repeat/dehydration response element binding factor 1 gene confers elevated tolerance to chilling and oxidative stresses in transgenic tomato. Plant Physiol. 129: 1086-1094.

Huang J., Sun S.J., Xu D.Q., Yang X., Bao Y.M., Wang Z.F. (2009) Increased tolerance of rice to cold, drought and oxidative stresses mediated by the overexpression of a gene that encodes the zinc finger protein ZFP245. Biochem. Biophys. Res. Commun. 389: 556-561.

Javot H., Maurel C. (2002) The role of aquaporins in root water uptake. Ann. Bot. 90: 301-313.

Kay S., Fiszbein A., Opler L. (1987) The Positive and Negative Syndrome Scale (PANSS) for schizophrenia. Schizophrenia Bull. 13: 262-276.

Khan S., Singh (2008) Abiotic Stress and Plant Responses. IK International, New Delhi: 159-189.

Liao Y., Zhang J. S., Chen S. Y. and Zhang W. K. (2008) Role of soybean GmbZIP132 under abscisic acid and salt stresses. J. Integrat. Plant Biol. 50: 221-230.

Liu Q., Kasuga M., Sakuma Y., Abe H., Miura S., YamaguchiShinozaki K., Shinozaki K. (1998) Two transcription factors, DREB1 and DREB2, with an EREBP/AP2 DNA binding domain separate two cellular signal transduction pathways in drought-and low-temperature-responsive gene expression, respectively, in Arabidopsis. Plant Cell 10: 1391-1406.

Ludwig A.A., Saitoh H., Felix G., Freymark G., Miersch O., Wasternack C., Boller T., Jones J.D., Romeis T. (2005) Ethylene mediated cross-talk between calcium-dependent protein kinase and MAPK signalling controls stress responses in plants. PNAS 102: 10736-10741.

Ma S., Gong Q., Bohnert H.J. (2006) Dissecting salt stress pathways. J. Exp. Bot. 57: 1097-1107.

Maggio A., De Pascale S., Angelino G., Ruggiero C., Barbieri G. (2004) Physiological response of tomato to saline irrigation in long term salinized soils. Eur. J. Agron. 21: 149-159.

Molendijk A.J., Ruperti B., Palme K. (2004) Small GTPases in vesicle traffcking. Curr. Opin. Plant Biol. 7: 694-700.

Mukhopadhyay A., Vij S., Tyagi A.K. (2004) Overexpression of a zinc-finger protein gene from rice confers tolerance to cold, dehydration, and salt stress in transgenic tobacco. PNAS 101: 6309-6314.

Murashige T., Skoog F. (1962) A Revised Medium for Rapid Growth and Bioassay with Tobacco Cultures. Physiol. Plant. 15: 473-496.
Munns R. (2005) Genes and salt tolerance: bringing them together. New Phytol. 167: 645-663.

Munns R., Tester M. (2008) Mechanisms of salinity tolerance. Ann. Rev. Plant Biol. 59: 651-681.

Nakashima K., Tran L.S., Van Nguyen D., Fujita M., Maruyama K., Todaka D., Ito Y., Hayashi N., Shinozaki K., Yamaguchi-Shinozaki K. (2007) Functional analysis of a $N A C$-type transcription factor OsNAC6 involved in abiotic and biotic stress-responsive gene expression in rice. Plant J. 51: 617-630.

Ni Y., Wang X., Li D., Wu Y., Xu W., Li X. (2008) Novel cotton homeobox gene and its expression profiling in root development and in response to stresses and phytohormones. Acta Biochim. Biophys. Sin. (Shanghai) 40: 78-84.

Olsen A.N., Ernst H.A., Lo Leggio L., Skriver K. (2005) NAC transcription factors: structurally distinct, functionally diverse. Trends Plant Sci. 10: 79-87.

Ouyang B., Yang T., Li H.X., Zhang L., Zhang Y.Y., Zhang J.H. (2007) Identification of early salt stress response genes in tomato root by suppression subtractive hybridization and microarray analysis. J. Exp. Bot. 58: 507-520.

Patel A.D., Pandey A.N. (2008) Effect of salinisation of soil on growth, water status and nutrient accumulation in seedlings of Holopteleaintegrifolia (Ulmaceae) Planch in response to soil salinity. Plant Soil Environ. 54: 367-373.

Plett D.C., Moller I.S. (2010) $\mathrm{Na}^{+}$transport in glycophytic plants: what we know and would like to know. Plant Cell Environ. 33: 612-626.

Qing D.J., Lu H.F., Li N., Dong H.T., Dong D.F., Li Y.Z. (2009) Comparative profiles of gene expression in leaves and roots of maize seedlings under conditions of salt stress and the removal of salt stress. Plant Cell Physiol. 50: 889-903.

Roy C., Sengupta D.N. (2014) Effect of Short Term NaClStress on Cultivars of S. lycopersicum: A Comparative Biochemical Approach. J. Stress Physiol. Biochem. 10: 59-81.

Sakamoto H., Maruyama K., Sakuma Y., Meshi T., Iwabuchi M., Shinozaki K., Yamaguchi-Shinozaki K. (2004) Arabidopsis Cys2/His2-type zinc-finger proteins function as transcription repressors under drought, cold, and high-salinity stress conditions. Plant Physiol. 136: 2734-2746.

Selth A., Dogra S.C., Rasheed M.S., Healy H., Randles J.W., Rezaian M.A. (2005) ANAC domain protein interacts with tomato leaf curl virus replication accessory protein and enhances viral replication. Plant Cell 17: 311-325.

Serrano R., Culiañz-Macia F.A., Moreno V. (1999) Genetic engineering of salt and drought tolerance with yeast regulatory genes. Sci. Hort. 78: 261-269.

Shope J.C., Mott K.A. (2006) Membrane trafficking and osmotically induced volume changes in guard cells. J. Exp. Bot. 57: 4123-4131.

Sreenivasulu N., Sopory S.K., KaviKishor P.B. (2007) Deciphering the regulatory mechanisms of abiotic stress tolerance in plants by genomic approaches. Gene 388: 1-13.

Talei D., Valdiani A., Yusop M.K., Abdullah M.P. (2013) Estimation of salt tolerance in Andrographis paniculata accessions using multiple regression model. Euphytica 189: 147-160. 
Tao Z., Kou Y., Liu H., Li X., Xiao J., Wang S. (2011) Os WRKY45 alleles play different roles in abscisic acid signalling and salt stress tolerance but similar roles in drought and cold tolerance in rice. J. Exp. Bot. 62: 4863-4874.

Tester M., Davenport R. (2003) $\mathrm{Na}^{+}$tolerance and $\mathrm{Na}^{+}$transport in higher plants. Ann. Bot. 91: 503-507.

Thomashow M.F. (2010) Molecular basis of plant cold acclimation: insights gained from studying the $C B F$ cold response pathway. Plant Physiol. 154: 571-577.

Xiong L., Zhu J.K. (2002) Salt tolerance. In: Arabidopsis Book. Eds. Somerville C., Meyerow-itz E. The American Society of Plant Biology, Rockville: 1-24.

Yamaguchi-Shinozaki K., Shinozaki K. (2006) Transcriptional regulatory networks in cellular responses and tolerance to dehydration and cold stresses. Ann. Rev. Plant Biol. 57: 781-803.

Zhang H.X., Blumwald E. (2001) Transgenic salt-tolerant tomato plants accumulate salt in foliage but not in fruit. Nature Biotech. 19: 765-768.
Zhang J.Z. (2004) From laboratory to field. Using information from Arabidopsis to engineer salt, cold and drought tolerance in crops. Plant Physiol. 135: 615-621.

Zhou Q.Y., Tian A.G., Zou H.F., Xie Z.M., Lei G., Huang J., Wang C.M., Wang H.W., Zhang J.S., Chen S.Y. (2008) Soybean WRKY-type transcription factor genes, GmWRKY13, GmWRKY21, and GmWRKY54, confer differential tolerance to abiotic stresses in transgenic Arabidopsis plants. Plant Biotech. J. 6: 486-503.

Zhu J.K. (2001) Plant salt tolerance. Trends Plant Sci. 6: 6671.

Zhu J.K. (2002) Salt and drought stress signal transduction in plants. Ann. Rev. Plant Biol. 53: 247-273.

Zhu J.K. (2003) Regulation of ion homeostasis under salt stress. Curr. Opin. Plant Biol. 6: 441-445. 